\title{
CHITOSAN NANOPARTICLES AS A DRUG DELIVERY SYSTEM FOR 1,2,4- TRIAZOLE DERIVATIVES: RELEASE AND ANTIMICROBIAL ACTIVITY.
}

\author{
Nehal Salahuddin ${ }^{1 *}$, Ahmed A. Elbarbary ${ }^{2}$, Mohamed L. Salem ${ }^{3}$, Samar Elksass ${ }^{4}$ \\ *1,2,3,4 Department of Chemistry, Faculty of Science, Tanta University, Tanta 31527, Egypt. \\ ${ }^{3}$ Department of zoology, Faculty of Science, Tanta University, Tanta 31527, Egypt.
}

"Corresponding Author: -

E-mail:nehal.attaf@science.tanta.edu.eg, salahuddin.nehal@yahoo.com

\begin{abstract}
: -
Chitosan (CS) 1,2,4-triazole derivatives including in the formulation tripolyphosphate (TPP) as crosslinking agent was prepared by a simple one step method using ultrasonic technique. The resultant nanoparticles were characterized by $x$ ray diffraction (XRD), Fourier transform infrared analysis (FT-IR), thermal gravimetric analysis (TGA), derivative thermal gravimetric analysis (D-TGA), transmission electron microscopy (TEM) and scanning electron microscopy (SEM). The results indicate that spherical nanoparticles with an average size of 21, 14.6, 23.95, $29.5 \mathrm{~nm}$ and their standard deviation $(S D)$ were $\pm 5, \pm 5.3, \pm 5.3, \pm 7.9 \mathrm{~nm}$ for CSTPP, CSTPPIII, CSTPPIV and CSTPPV, respectively were successfully prepared. The in vitro release and mechanism of 1,2,4-triazoles at different $p H$ values was investigated. From values of $R^{2}$ the mechanism of drug release is following zero order mechanism at $p H$ 6.8; however in $p H 2$, CSTPPIII, CSTPPIV and CSTPPV are following Hixson-Crowell, zero order and Korsmeyer-Peppas equation, respectively.The antibacterial activity against the gram negative bacteria and gram positive bacteria was examined.
\end{abstract}

Keywords: - Chitosan nanoparticles, 1,2,4-Triazole derivatives, Sodium tripolyphosphate, Ionic gelation, In vitro release, antimicrobial activity.

\section{(c) $(\$)$ (i)}




\section{INTRODUCTION}

Nanoparticle systems offer many advantages in drug delivery by improving the stability of the drug against chemical and enzymatic degradation, extending the therapeutic effect of the drug at the target site and improving bioavailability. ${ }^{[1]} \mathrm{CS}$ is a naturally occurring nontoxic, cationic polysaccharide composed of randomly distributed $(1 \rightarrow 4)$ linked D-glucosamine and N-acetyl-D-glucosamine units and presents welldocumented favorable properties for drug delivery such as biodegradable, bioadhesive, promotes woundhealing and has bacteriostatic effects. ${ }^{[2]}$

CS contains abundant amino and hydroxyl groups which facilitate the formulation of nanoparticles via physical and chemical crosslinking. Several techniques have been developed to prepare CS nanoparticles as emulsion crosslinking, ionic gelation and spray drying technique. Crosslinking is usually achieved by reaction with dialdehydes such as glutaraldehyde and epichlorohydrin. However, they are toxic and can cause irritation to mucosal membranes. ${ }^{[3]}$

Ionic crosslinking of CS is a typical non-covalent interaction, which can be realized by association with negatively charged multivalent ions such as TPP. For pharmaceutical application, physical crosslinking is more favorable since the crosslinking is reversible and may largely avoid potential toxicity of the reagents used in chemical crosslinking. ${ }^{[4]}$ Optimization of the fabrication conditions and comprehensive properties of the resultant CS nanoparticles is still an ongoing important topic in this field. The size of nanoparticles affects not only the release performance but also govern the interaction of the particles with different biological tissues where they are introduced.

The chitosan-tripolyphosphate (CSTPP) nanoparticles, composed of food-safe ingredients, has shown its capacity for the encapsulation and delivery of Bovine serum albumin $(\mathrm{BSA})^{[5]}$, hydrophilic and hydrophobic drugs ${ }^{[6]}$, rutin ${ }^{[7]}$, essential oil $^{[8]}$, catechins, ${ }^{[9]}$ Amoxicillin trihydrate and Metronidazole. ${ }^{[10]}$

1,2,4-Triazoles have an effective antibacterial activity against both Gram-positive and Gram-negative bacteria, antifungal, antitubercular, anti-inflammatory, anti-convulsant, antiviral, antitumor and antispastic agents. ${ }^{[11]}$

To reduce the effect of 1,2,4-triazole toxicity upon using for long term application, the objective of this work was directed to produce CS/1,2,4-triazole nanoparticles including in the formulation TPP as crosslinking agent by a simple method using ultrasonic technique. Reduced size would improve the loading capacity and effect on the release rate. The morphology and composition of the nanoparticles was investigated using XRD, FT-IR, TEM, SEM, TGA and D-TGA. Moreover, the release kinetics was evaluated. In addition the efficiency against Gram positive and Gram negative bacteria was studied.

\section{Materials and Methods \\ Materials}

CS (Across organics, USA, Mw. 100,000-300,000; deacetylation degree (DD) 90\%), TPP, phenyl isothiocyanate (Across organics, USA), dimethyl sulfoxide (DMSO) (Sigma-Aldrich), Hydrazine mono hydrate (Laboratory rasayan), Nutrient agar (Alpha chemicke), ethyl benzoate (fabricaclon Alemana), ammonium thiocyanate (Win Lab), methyl-2-hydroxy benzoate, sodium hydroxide, concentrated hydrochloric acid $(\mathrm{HCl})$ and acetic acid, mono, di sodium phosphate, acetic acid (Adwic, Egypt) were purchased and used as received. Thin layer chromatography (TLC) was carried out with silicagel precoated plastic sheets.

\section{Instruments}

FT-IR spectra were recorded on Bruker, Tensor 27 FT-IR spectro-photometer with frequency range $4000 \mathrm{~cm}^{-1}$ to $400 \mathrm{~cm}^{-}$ ${ }^{1}$ using $\mathrm{KBr}$ pressed disc technique. XRD were carried out using GRN, APD 2000 PRO X-Ray diffraction, equipped with a Ni-filtered $\mathrm{Cu}-\mathrm{K} \alpha$ radiation $\left(\lambda=1.54 \mathrm{~A}^{\circ}\right)$ at a scanning rate of $0.02^{\circ}$ per second and diverged slit $0.3^{\circ}(\mathrm{Central} \mathrm{Lab}$. Tanta University, Egypt). TGA data were obtained using Shimadzu thermal analyzer system at a heating rate of $10{ }^{\circ} \mathrm{C} / \mathrm{min}$, sample weight of $5-6 \mathrm{mg}$, under nitrogen $(20 \mathrm{ml} / \mathrm{min})$ flow. The range investigated from $25-800{ }^{\circ} \mathrm{C}$. TGA-50 furnace with a M3 microbalance, and TA72 Graph ware software were employed for thermal analyses (Microanalysis center, Cairo University, Giza, Egypt). TEM micrographs were taken with a JEOL JEM-1230 electron microscope at an accelerating voltage of $100 \mathrm{KV}$ (Faculty of Medicine, Tanta University, Egypt). SEM micrographs were taken with JEOL JSM 6360 LA Analytical SEM at an accelerated voltage $10 \mathrm{KV}$. SEM samples were prepared by coating with gold (Science Research and Technological applications city, New Burg El Arab city, Alexandria, Egypt). UV-Vis absorption spectra were obtained using a shimaduza UV- visible 2101 PC spectrophotometer. All melting points (m.p.) measured in open capillary tubes using stuart scientific melting point apparatus SMP3 and are uncorrected.

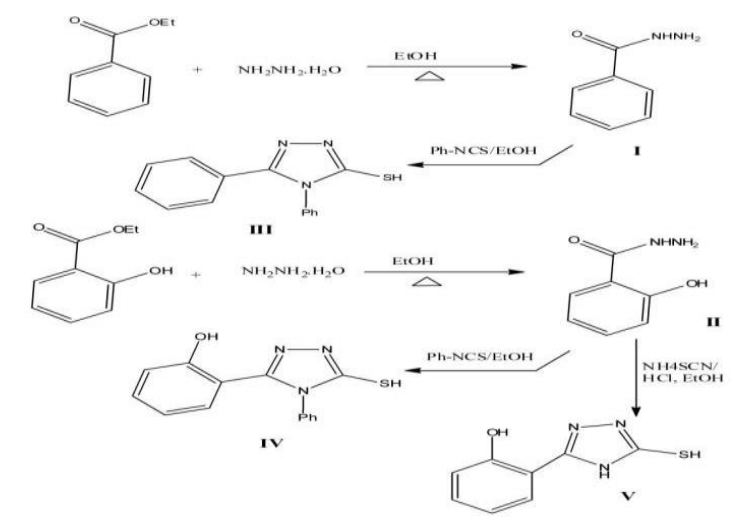

Scheme 1: Preparation of 1,2,4-triazole derivatives (III-IV). 


\section{Methods}

4,5-Diphenyl-4H-1,2,4-triazole-3-thiol (III), 2-(5-mercapto-4-phenyl-4H-1,2,4-triazol-3-yl) phenol (IV) and 2(5mercapto-4H-1,2,4-triazol-3-yl) phenol (V) were prepared (Scheme1) according to recommended methods as follows

\section{Preparation of III and IV}

A mixture of 2-substituted benzohydrazide (I, II) $(0.01 \mathrm{~mol})$, phenyl isothiocyanate $(0.01 \mathrm{~mol})$ in $20 \mathrm{ml}$ absolute ethanol was refluxed (TLC). The solvent was distilled under reduced pressure; the residual solid was refluxed with sodium hydroxide $(0.12 \mathrm{~mol})$ for $3 \mathrm{~h}$. The resulting solution was acidified with $\mathrm{HCl}$. The product was separated, dried and recrystallized from dilute ethanol to give (III, IV). Compound (III) yield 89\%, m.p. 290- $292{ }^{\circ} \mathrm{C}$, (IV) yield 88\%, m.p. $300-301{ }^{\circ} C^{[12,13]}$

\section{Preparation of V}

A mixture of 2-hydroxy benzohydrazide (II) $(0.01 \mathrm{~mol})$, ammonium thiocyanate $(0.03 \mathrm{~mol})$, and $4 \mathrm{ml}$ hydrochloric acid in $200 \mathrm{ml}$ ethanol was refluxed (TLC). The solvent was distilled under reduced pressure; the residual solid was refluxed in $4 \% \mathrm{NaOH}$ for $3 \mathrm{~h}$. The resulting solution was acidified with $\mathrm{HCl}$. The product was filtered off, dried and recrystallized from dilute ethanol to give (V) yield $85 \%$, m. p. $287-288^{\circ} \mathrm{C} \cdot{ }^{[13]}$

\section{Preparation of CSTPP nanoparticles}

CSTPP were prepared by ionotropic gelation of CS in the presence of TPP anions using (CS:TPP; 2.3:1) molar ratio. TPP ( $1 \mathrm{~g}$ dissolved in distilled water) was added to CS solution (CS $1 \mathrm{~g}$ dissolved in $100 \mathrm{ml}$ of $1 \%$ acetic acid) during sonication for 15 minutes at $30^{\circ} \mathrm{C}$. The mixture was stirred for 45 minutes, CSTPP nanoparticles were centrifuged the supernatant was discarded and the deposit was re-dispersed in distilled water for three times and dried at $40{ }^{\circ} \mathrm{C}$.

\section{Preparation of CSTPPIII, CSTPPIV and CSTPPV nanoparticles.}

( $0.0011 \mathrm{~mol})$ of 1,2,4-triazole derivatives III was added to CS solution (1 $\mathrm{g}$ was dissolved in $80 \mathrm{ml}$ of $1 \%$ acetic acid) and stirred for 30 minutes. TPP ( $1 \mathrm{~g}$ dissolved in distilled water) was added during sonication for 15 minutes followed by stirring for $2 \mathrm{~h}$. The products were separated using centrifuge and dried at $40^{\circ} \mathrm{C}$ to afford CSTPPIII. The same method was used to prepare CSTPPIV and CSTPPV.

\section{Adsorption efficiency}

The amount of 1,2,4-triazole derivatives in the initial solution and supernatant was determined by UV-Vis spectrophotometer to determine the adsorption efficiency (Table1).

\section{Drug Release}

Phosphate buffer solutions ( $\mathrm{PB}$ ) were prepared by dissolving di and mono sodium phosphate in deionized water, the $\mathrm{pH}$ was adjusted at 6.8. For $\mathrm{pH} 2$ drops of concentrated $\mathrm{HCl}$ were added to deionized water until $\mathrm{pH}$ adjusted to 2 .

\section{Release Measurements}

10 milligrams of samples in $1 \mathrm{ml}$ buffer were dialyzed in dialysis membrane bag which is put in $100 \mathrm{ml}$ of the PB (pH 6.8) or acidic solution ( $\mathrm{pH}$ 2). The concentration of 1,2,4-triazole derivatives were determined by using UV- Vis spectrophotometer at $\lambda_{\max }=261,263$ and $255 \mathrm{~nm}$ for III, IV and V, respectively. At each time, $3 \mathrm{ml}$ of the buffer was collected for analysis.

\section{In vitro release kinetic and mechanism}

Data obtained from in vitro release studies were analyzed by fitting to the following equations

Zero-order release kinetics: $\quad W=W_{\mathrm{o}}+k_{\mathrm{o}} t$

First-order release kinetics: $\quad \log (100-W)=\log 100-k_{1} t$

Higuchi model: $\quad W=k_{H} t^{1 / 2}$

Hixson-Crowell Kinetics: $\quad(W-100)^{1 / 3}=100^{1 / 3}-k_{\text {Hix }} t$

Korsmeyer-Peppas equation: $\quad F=\frac{M_{t}}{M_{\infty}}=k_{a} t^{n}$

Where $\mathrm{k}_{\mathrm{o}}, \mathrm{k}_{1}, \mathrm{k}_{\mathrm{H}}, \mathrm{k}_{\mathrm{Hix}}, \mathrm{k}_{\mathrm{a}}$ are drug release rate constants, $\mathrm{W}$ is the percent released of drug at time $\mathrm{t}, \mathrm{W}_{\mathrm{o}}$ is the cumulative drug release at $t=0, F=M_{t} / M_{\infty}$ is a fraction of 1,2,4-triazole derivatives released at time $t$ into dissolution media, $M_{t}$ is the concentration of triazoles with time $t, M_{\infty}$ is the maximum amount absorbed, $n$ is the release exponent that shows the release of 1,2,4-triazoles transport mechanism.

\section{In Vitro Antimicrobial Activity}

The microbial strains were obtained from Bacteriological laboratory of Botany department, Microbiology section, Faculty of science, Tanta University. The Gram-negative bacteria (Escherichia coli ATCC 8739, Pseudomonas aeruginosa ATCC 9027) and Gram-positive bacteria (Staphylococcus aureus ATCC 6633, Staphylococcus epidermidis ATCC 12228) were used to examine the antimicrobial activity of the nanoparticles. The bacterial strains were maintained on nutrient agar (3 $\mathrm{g}$ peptone; $5 \mathrm{~g} \mathrm{NaCl} ; 5 \mathrm{~g}$ beef extract; $28 \mathrm{~g}$ nutrient agar per liter, $\mathrm{pH}=7.4$ ). 1,2,4-Triazole derivatives (III-V), CS, CSTPP, and CS/ 1,2,4-triazole/TPP (CSTPPIII, CSTPPIV, CSTPPV) were screened for their antimicrobial activity against the 
above bacterial strains. The bacteria strains were maintained on nutrient agar and nutrient broth. All media were sterilized in autoclave before experiments. The inoculum's concentrations were $6.5 \times 10^{5} \mathrm{CFU}$. After incubation for $24 \mathrm{~h}$, the agar plates were checked for the diameter of inhibition zone. The antimicrobial activity of the tested samples was determined by well diffusion method. Powder samples $(20 \mathrm{mg} / \mathrm{ml})$ were dispersed in DMSO. DMSO was used as negative control. The plates were incubated at $37^{\circ} \mathrm{C}$ for $24 \mathrm{~h}$, after which they were examined for inhibition zones development. A caliper was used to measure the inhibition zones. Three replicates were carried out. The antimicrobial effect of triazole derivatives, CS and triazole loaded nanoparticles on the microorganism was determined by the size of the inhibitory zone.

\section{Results and discussion}

The present work develops a simple one step process for synthesis CS/1,2,4-triazole/TPP nanoparticles using ultrasonic technique. First CS was dissolved in acetic acid and mixed with 1,2,4-triazole derivatives to obtain 1,2,4-triazole/CS solution followed by addition of TPP to prepare cross-linked CS nanoparticles.

\section{IR spectra analysis}

Fig 1 represent FT-IR spectra of CS, TPP, CSTPP, triazole derivatives (III-V) and triazoles loaded nanoparticles (CSTPPIII, CSTPPIV and CSTPPV). In the spectrum of CS, the band at $3437 \mathrm{~cm}^{-1}$ is assigned to $\mathrm{OH} \mathrm{and} \mathrm{NH}_{2}, 2921 \mathrm{~cm}^{-}$ ${ }^{1}$ (C-H stretching), 1649 and $1425 \mathrm{~cm}^{-1}$ ( $\mathrm{C}=\mathrm{O}$ stretching amide I and $\mathrm{NH}$ stretching amide II), $1383 \mathrm{~cm}^{-1}\left(\mathrm{CH}_{3}\right.$ in amide group), $1153 \mathrm{~cm}^{-1}$ (anti-symmetric stretching of C-O-C bridge) $1095 \mathrm{~cm}^{-1}, 1010 \mathrm{~cm}^{-1}$ (skeletal vibration involving the CO stretching). ${ }^{[14]}$ In the spectrum of TPP, the band at $1217 \mathrm{~cm}^{-1}$ is assigned to (P-O stretching), 1149 and $898 \mathrm{~cm}^{-1}$ (symmetric and anti-symmetric stretching vibrations in $\mathrm{PO}_{2}$ group respectively), $1069 \mathrm{~cm}^{-1}$ (symmetric and antisymmetric stretching vibrations in $\mathrm{PO}_{3}$ group and antisymmetric stretching of the P-O-P Bridge). ${ }^{[15]}$ In the spectrum of triazoles (III-V), the peaks at $660-770 \mathrm{~cm}^{-1}$ are assigned to mono substituted and di substituted aromatic ring, $2930 \mathrm{~cm}^{-1}$ related to $\mathrm{C}-\mathrm{H}$ aliphatic, $3038 \mathrm{~cm}^{1}$ and $3326 \mathrm{~cm}^{-1}$ assigned to $\mathrm{C}-\mathrm{H}$ aromatic and $\mathrm{O}-\mathrm{H}$ group ,respectively.

FT-IR spectrum of CSTPP nanoparticles shows absorption band at $1542 \mathrm{~cm}^{-1}$ due to $\mathrm{NH}_{3}{ }^{+}$vibration. Moreover, the band at 3437 and $1649 \mathrm{~cm}^{-1}$ related to $\mathrm{OH}$ and $\mathrm{C}=\mathrm{O}$ stretching (amide I) were shifted to 3447 and $1624 \mathrm{~cm}^{-1}$ in CSTPP, implying electrostatic interaction between $\mathrm{NH}_{3}{ }^{+}$groups of $\mathrm{CS}$ and phosphoric groups of TPP within the nanoparticles. ${ }^{[16]}$ The spectrum of CSTPPIII, CSTPPIV and CSTPPV loaded triazoles nanoparticles show that the peaks at $3437 \mathrm{~cm}^{-1}$ related to O-H group was shifted to $3419,3328,3391 \mathrm{~cm}^{-1}$, respectively implying the inter action between CS and TPP within the nanoparticles. Moreover, peaks were observed at 1549,1543 and $1565 \mathrm{~cm}^{-1}$ implying the inter action between $\mathrm{NH}_{3}^{+}$ groups of CS and phosphoric groups of TPP within the nanoparticles in CSTPPIII, CSTPPIV and CSTPPV, respectively. It worth noting that a mixture of TPP, CS and III powders (Fig $1 \mathrm{CS} / \mathrm{TPP} / \mathrm{III}$ ) showed the same characteristic peaks for these compounds without any shift that confirm the interaction in nanoparticles.

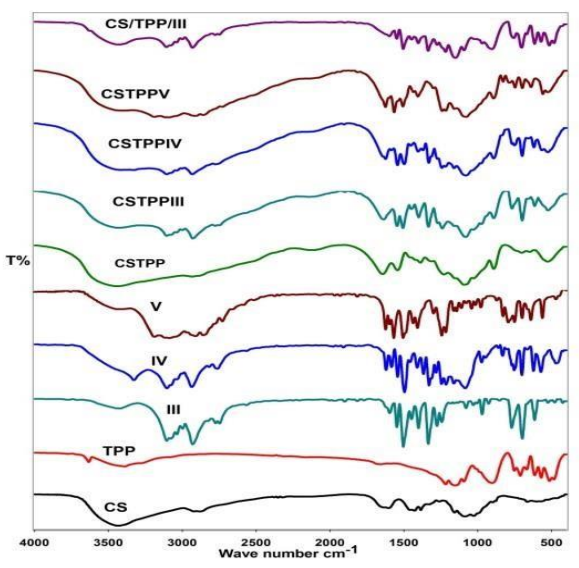

Figure 1: FT-IR of CS, TPP, 1,2,4-triazoles (III-V), CSTPP, CSTPPIII, CSTPPIV, CSTPPV and CS/TPP/III.

\section{Crystallographic assay}

Fig 2 shows the XRD patterns of CSTPP loaded by triazole derivatives as well as those of the parent CS, TPP, and 1,2,4triazole derivatives (III-IV). CS shows two characteristic peaks at $2 \theta=\left(10^{\circ}\right.$ and $\left.20.3^{\circ}\right)$. The presence of plenty of $-\mathrm{OH}$ and $-\mathrm{NH}_{2}$ groups in CS structure forms strong inter- and intra-molecular hydrogen bonds, thereby showing certain regularity in the CS structure. ${ }^{[14]}$ XRD of TPP showed many sharp peaks at $2 \theta=\left(18.5,18.9,19.2,19.8,21.8,29.1^{\circ}\right)$ indicates that TPP is in crystalline form.

In case of CSTPP nanoparticles a diffraction peak was observed at $2 \theta=17.20^{\circ}$ with broad peak at $2 \theta=24.37^{\circ}$. This could be attributed to modification in the arrangement of molecules in the crystal lattice, due to formation of electrostatic interaction between $\mathrm{NH}_{3}{ }^{+}$groups of CS and phosphoric groups of TPP.

As compared with CSTPP nanoparticles, CSTPPIII, CSTPPIV and CSTPPV nanoparticles, sharp peaks characteristic to III, IV, $\mathrm{V}$ at $2 \theta=9.1,12.1,19.4,20.1,25.6,26.8^{\circ}$ derived from triazole derivatives were observed confirming the presence of III, IV and V within CSTPP nanoparticles. The broadness of the peak at $2 \theta=17.2^{\circ}$ indicates that the incorporation of III, IV and V resulted in a change in the CSTPP packing structure. The ionic cross-linking of CS with TPP in CSTPP, leads to the destruction of the native CS packing structure. The broad peak of CS nanoparticles may be caused by the cross-linking reaction between CS and TPP, which may destroy the crystalline structure of CS. ${ }^{[16]}$ CS nanoparticles are 
comprised of a dense network structure of interpenetrating polymer chains cross linked to each other by TPP counter ions. ${ }^{[17]}$ The XRD implicated greater disarray in chain alignment in the nanoparticles after crosslinks. ${ }^{[18]}$ It is well-known that the width of XRD diffraction peak is related to the size of crystallite, the broadened peak usually results from imperfect crystal. ${ }^{[16]}$ Crystalline sizes of samples were estimated using Scherer's equation (1)

$$
D=\frac{k \lambda}{\beta \cos \theta_{(1)}}
$$

Where $\mathrm{k}=$ constant $(0.89<\mathrm{k}<1), \lambda$ wavelength of the $\mathrm{X}$-ray, $\mathrm{B}=\mathrm{FWHM}$ (full width at half maximum width of the diffraction peak, $\theta=$ diffraction angle. The average diameters of the nanoparticle were calculated. The highest three peaks were chosen to calculate the average diameters that were found to be 41.4, 25.4, $30.7 \mathrm{~nm}$ for CSTPPIII, CSTPPIV and CSTPPV, respectively.

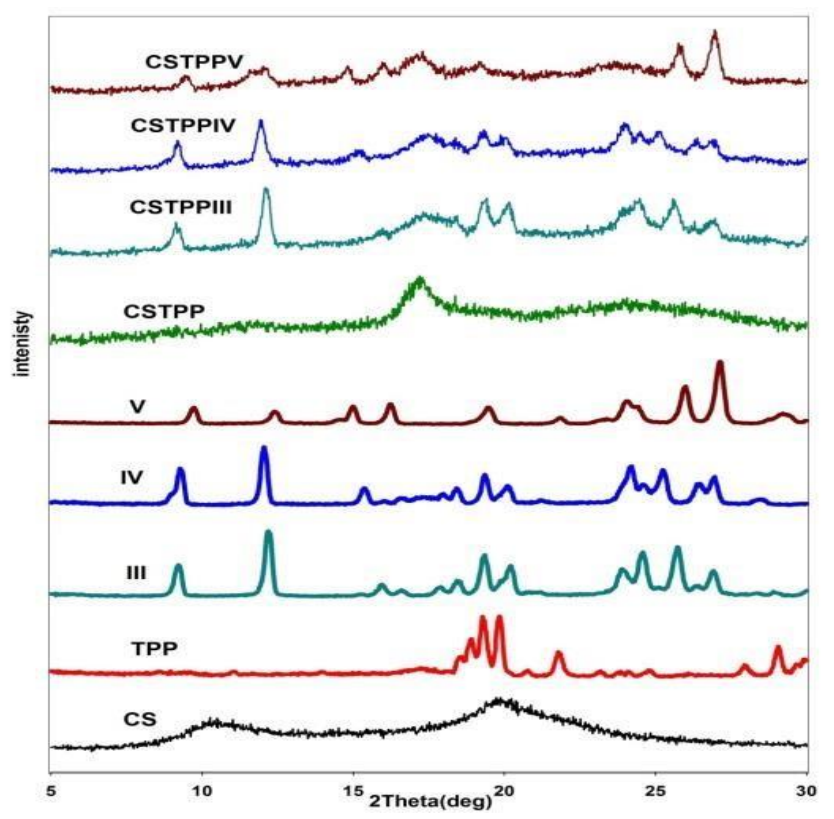

Figure 2: XRD of CS, TPP, 1,2,4-triazoles (III-V), CSTPP, CSTPPII, CSTPPIV and CSTPPV.

\section{Morphology}

The morphology of the particles was characterized by TEM observation (Fig 3).TEM images showed that the CSTPP has spherical shape with size average $21 \mathrm{~nm}$ and SD of \pm 5 (Fig 3a). The size distribution obtained by TEM indicated the average size of CSTPPIII, CSTPPIV and CSTPPV nanoparticles were 14.6, 23.95, $29.5 \mathrm{~nm}$ and their SD are $\pm 5.3, \pm 5.3$ and \pm 7.9 , respectively (Fig $3 b, c, d)$.

It was reported that ionic gelation of CS using TPP produce particles with spherical shape and diameter ranging from 309.8- $402.2 \mathrm{~nm}$ in oil loaded CSTPP nanoparticles ${ }^{[8]}$, and ranging from $322-814 \mathrm{~nm}$ as entrapped with rutin depending on CS ratios. ${ }^{[7]}$ In another publication, particle size of CSTPP nanoparticles loaded with Bovine serum albumin (BSA) was in range between 615 to $116 \mathrm{~nm}$ depending on concentration of calcium alginate. ${ }^{[5]}$ Ionically Cross-linked CSTPP microparticles were prepared for the controlled delivery of Pyrimethamine was produced in microparticles range. ${ }^{[6]}$ Moreover, loading of Amoxicillin trihydrate and Metronidazole for the treatment of gastric ulcer using CS gave microparticles in range of $10 \mu \mathrm{m}$ to $25 \mu \mathrm{m}$. $^{[10]}$

The morphology of the CSTPP and CSTPPIII nanoparticles was further characterized by SEM. Fig 4a,b depicts porous surface morphology. A spherical shape is observed for CSTPP with average size of $84 \mathrm{~nm} \mathrm{SD} \pm 7 \mathrm{~nm}$. These pores may allow water molecules to diffuse into the nanoparticles to form the large pores causes swelling of the nanoparticles. 

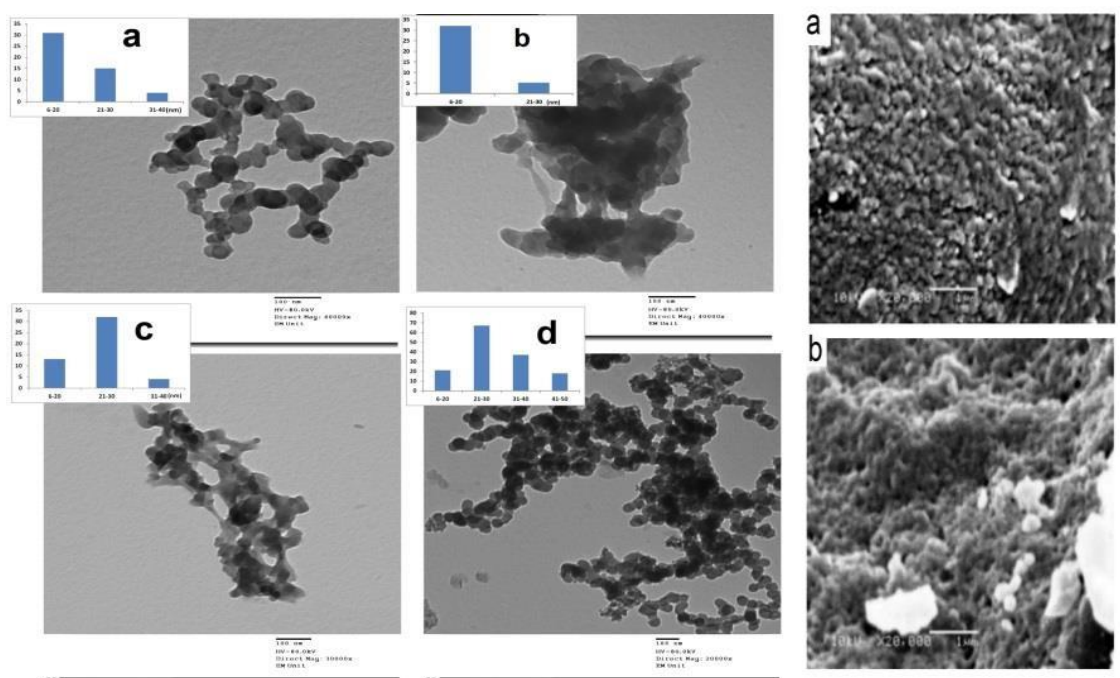

Figure 3: TEM of a: CSTPP, b: CSTPPIII, c: CSTPPIV and d: CSTPPV. Figure 4: SEM of a: CSTPP and b: CSTPPIII.

\section{Thermal properties}

To investigate the weight loss of nanoparticles loaded 1,2,4-triazole derivatives, TGA was performed under nitrogen atmosphere (Fig 5a, b). Three steps weight loss were observed in CSTPP (Fig 5b). The first step at $50110{ }^{\circ} \mathrm{C}$ can be attributed to the loss of moisture and bound water from the nanoparticles. The second weight loss from 200 to $350{ }^{\circ} \mathrm{C}$ can be assigned to degradation of the saccharide rings. The third step at 575 to $798{ }^{\circ} \mathrm{C}$ assigned to decomposition of the acetylated and deacetylated units of the polymer. ${ }^{[19]}$ The temperatures corresponding to the maximum slopes of each weight change step are clearly observed when the first derivative of the TGA curve with respect to temperature, the socalled D-TGA, is plotted (Fig 5b). The temperatures which give the highest rate of weight loss at each step (i.e., peaks in the D-TGA thermogram) are usually considered as degradation temperatures (Td) of components in the material. D-TGA for CSTPP showed degradation at 57.87, 229.39 and $747{ }^{\circ} \mathrm{C} .{ }^{[8]}$

TGA of CSTPPIII, CSTPPIV and CSTPPV showed four steps of weight loss. The first step of weight loss of CSTPPIII, CSTPPIV and CSTPPV in range from 27.46 to $171.49{ }^{\circ} \mathrm{C}$ (Fig 5a) and D-TGA showed Td at 61.08, 62.95 and $64.06{ }^{\circ} \mathrm{C}$, respectively (Fig 5b), this was attributed to the loss of absorbed and bound water. The second step of weight loss in range from 171 to $262{ }^{\circ} \mathrm{C}$ (Fig 5a) and D-TGA showed Td at 232.31, 232.03 and $224.96{ }^{\circ} \mathrm{C}$, respectively (Fig 5b), this can be assigned to degradation of the saccharide rings, depolymerization and decomposition of the acetylated and deacetylated units of the polymer. The third step in range from 262 to $375{ }^{\circ} \mathrm{C}$ (Fig 5a) and D-TGA showed Td at 287.01, 297.28 and $286.03{ }^{\circ} \mathrm{C}$, respectively (Fig 5b), this step confirms the incorporation of the 1,2,4-triazole derivatives into nanoparticles. The last step at 375 to $798{ }^{\circ} \mathrm{C}$ assigned to decomposition of the acetylated and deacetylated units of the polymer. The percentage weight loss at this temperature range was thus used to compute the amount of loaded 1,2,4-triazole derivatives (Table 1). In addition, the loading percentage of III-V on nanoparticles was calculated using UV-Vis Spectrophotometer (Table 1).

Table 1: Adsorption efficiency and percentage of loaded 1,2.4-triazole derivatives into nanoparticles calculated using TGA and UV-visible spectrophotometer.

\begin{tabular}{|c|c|c|c|}
\hline \multirow[t]{2}{*}{ Code } & \multirow[t]{2}{*}{$\begin{array}{c}\text { Adsorption } \\
\text { efficiency }\end{array}$} & \multirow{2}{*}{$\begin{array}{c}\text { Percentage of loaded } \\
\text { 1,2,4 nanoparticles }\end{array}$} & -triazole derivatives into \\
\hline & & & $\begin{array}{ccc}\text { By } & \text { using } & \text { UV-visible } \\
\text { Spectrophotometer }\end{array}$ \\
\hline CSTPPIII & $70.4 \%$ & $22.5 \%$ & $22 \%$ \\
\hline CSTPPIV & $71.6 \%$ & $23.05 \%$ & $22.09 \%$ \\
\hline CSTPPV & $57.2 \%$ & $23.07 \%$ & $19.086 \%$ \\
\hline
\end{tabular}




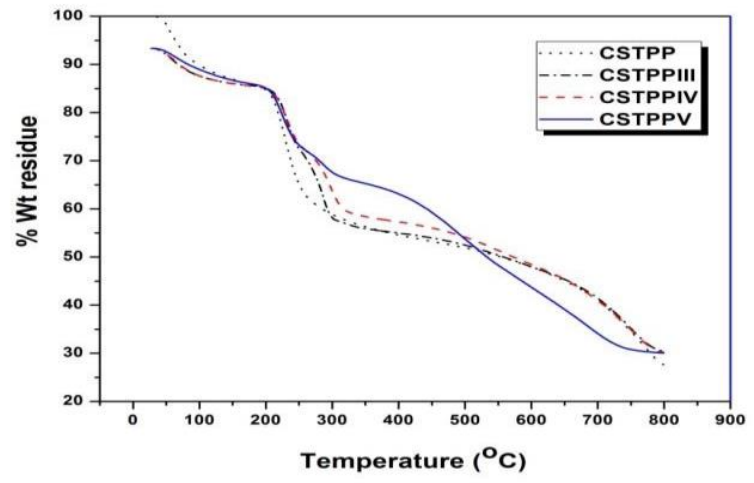

Figure 5a: TGA of CSTPP, CSTPPIII, CSTPPIV and CSTPPV.

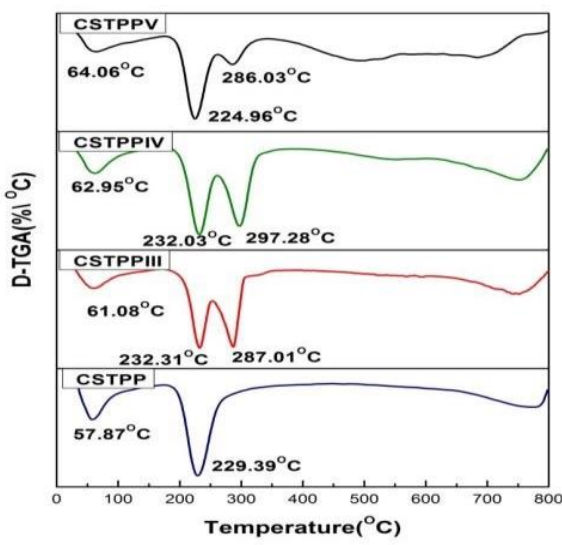

Figure 5b: D-TGA of CSTPP, CSTPPIII, CSTPPIV and CSTPPV.

\section{Antimicrobial Activity}

The capability of the 1,2,4-triazole derivatives, CS, CSTPP and CS-triazole-TPP nanoparticles to inhibit the growth of the selected micro-organisms on solid media is shown in Fig 6. All compounds can't inhibit the growth of Pseudomonas aeruginosa and Staphylococcus epidermidis. However, all compounds show antibacterial activity against Escherichia coli and Staphylococcus epidermidis. CS and CSTPP have similar antimicrobial effect against Escherichia coli and Staphylococcus aureus. The antibacterial activity of CS under acidic environment may result from its polycationic structure due to the protonation of $-\mathrm{NH}_{2}$ on the $\mathrm{C}-2$ position of the D-glucosamine. Positively charged $\mathrm{CS}$ can bind to bacterial cell surface which is negatively charged and disrupt the normal functions of the membrane, by promoting the leakage of intracellular components or by inhibiting the transport of nutrients into cells. ${ }^{[20]}$ Phosphate ion reacts with Gram-positive bacteria by the same mechanism of CS without need to acid medium since phosphate present as ion in CSTPP nanoparticles. Compound III and CSTPPIII nanoparticles have the similar antimicrobial effect against Escherichia coli and Staphylococcus aureus (11.5 and $19 \mathrm{~mm}$, respectively). However IV and V show little higher antimicrobial activity in comparison with CSTPPIV, CSTPPV nanoparticles, respectively. It was worthmentioning that the concentration of III, IV, and V in CSTPPIII, CSTPPIV, and CSTPPV is 22.5- 23\% (Table1). This indicates the nanoparticle has higher activity due to the small particle size.

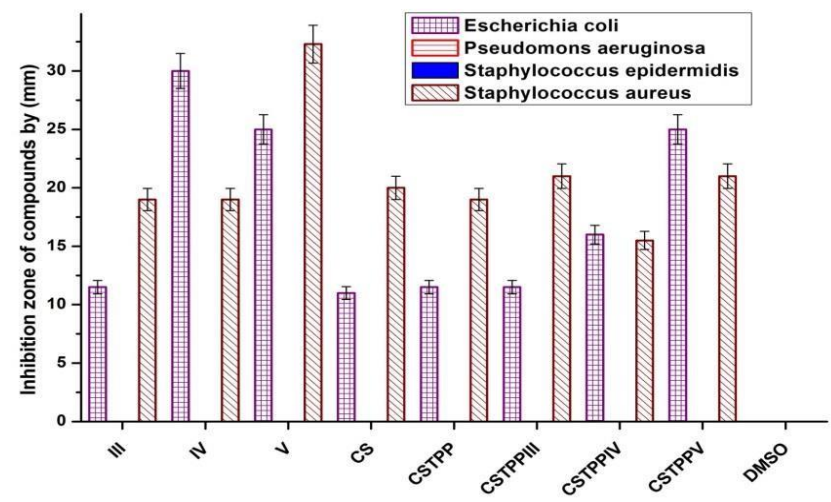

Figure 6: Inhibition zones of DMSO, 1,2,4-triazoles (III-V), CS, CSTPP, CSTPPIII, CSTPPIV and CSTPPV. 


\section{Release Profiles}

The in vitro release of triazols (III-V) from CSTPP nanoparticles was studied in different $\mathrm{pH}$ values $(2 \mathrm{and} 6.8)$ for $50 \mathrm{~h}$ at $40{ }^{\circ} \mathrm{C}$. The concentration was measured during time intervals by UV-Vis spectrophotometer. A gradual release was observed at pH 2 and 6.8 (Fig 7). The maximum release of triazoles from nanoparticles in both pH values was observed to be in the range $20-45 \%$ after $70 \mathrm{~h}$ based on the release profile at $\mathrm{pH} 2$ and 6.8 . This is probably due to the existence of interaction between $\mathrm{NH}_{2}, \mathrm{OH}$ groups in $\mathrm{CS}$ and $\mathrm{OH}$ in triazoles that delay the release. It was reported that the maximum release of rutin from CSTPP was $20 \%$. This indicates that $80 \%$ of rutin was still trapped within the particles. ${ }^{[7]}$ Also, it was reported that $45-55 \%$ of catechin was released from CSTPP depending on the mass ratio of TPP after $12 \mathrm{~h}$ emersion in distilled water at $37^{\circ} \mathrm{C}$. ${ }^{[9]}$

The release of triazoles from nanoparticles was $\mathrm{pH}$ dependent; they showed significantly faster release in strong acidic media ( $\mathrm{pH}$ 2) than slightly acidic media ( $\mathrm{pH}$ 6.8). There are a plenty number of amino and hydroxyl groups on CS molecules, that provides favorable functional groups to biological molecules. In strong acidic media, the release is relatively rapid in comparison with weak acidic media. This is attributed to the electrostatic repulsion between $\mathrm{NH}_{3}{ }^{+}$ groups that increase intra particles places in the nanoparticle. In contrast to weak acidic media $\mathrm{NH}_{2}$ groups that mainly attached to the surface of CS slow down the release rate of the biological molecules.

It is worth nothing that CSTPPIV, CSTPPV showed a fast release rate in comparison with CSTPPIII, this may be attributed to the presence of $\mathrm{OH}$ group that favor the release. The hydrophobicity in CSTPPIII combined with the crosslinking density imparted delay for the release. Moreover, CSTPPV showed a larger cumulative amount release than CSTPPIV. The fast release is due to an increase in the hydrophilicity due to presence of phenyl group in CSTPPIV.

Similar results were obtained in CSTPP entrapped with rutin that showed no release after 2 hours in simulated gastric fluid (SGF) ( $\mathrm{pH}$ 1.4) indicating that rutin-CS interactors remained relatively strong. ${ }^{[7]}$ In contrast, it was reported that catechin release from CSTPP in SGF to range between 5 to $15 \%$ depending on TPP\% and the interaction between catechin and CS. ${ }^{[9]}$ Another study recorded that $20-40 \%$ of bovine serum albumin was released from CS TPP nanoparticles after 20 min in simulated intestinal fluid (SIF) with enzymes. ${ }^{[5]}$

Release kinetics for nanoparticles was analyzed by assessing the fitting of release data to the above kinetic equations (Fig 8, Fig 9). By applying kinetic equations, the release constant $\left(\mathrm{k}_{\mathrm{o}}, \mathrm{k}_{1}, \mathrm{k}_{\mathrm{H}}, \mathrm{k}_{\mathrm{Hix}}\right.$ and $\left.\mathrm{k}_{\mathrm{a}}\right)$ are obtained from plot of kinetic model in addition to correlation $\mathrm{R}^{2}$ and for Korsmeyer-Peppas equation the release exponent value $\mathrm{n}$ was obtained (Table 2). From value of $\mathrm{R}^{2}$ the mechanism of drug release in CSTPPIII, CSTPPIV and CSTPPV at $\mathrm{pH} 2$ is following Zero-order kinetics, however, in $\mathrm{pH} 6.8$ is following HixsonCrowell, Zero-order kinetics and Korsmeyer-Peppas equation, respectively. From Korsmeyer-Peppas equation the value $\mathrm{n}$ was found to be more than 0.5 then the release through anomalous non fickian diffusion.

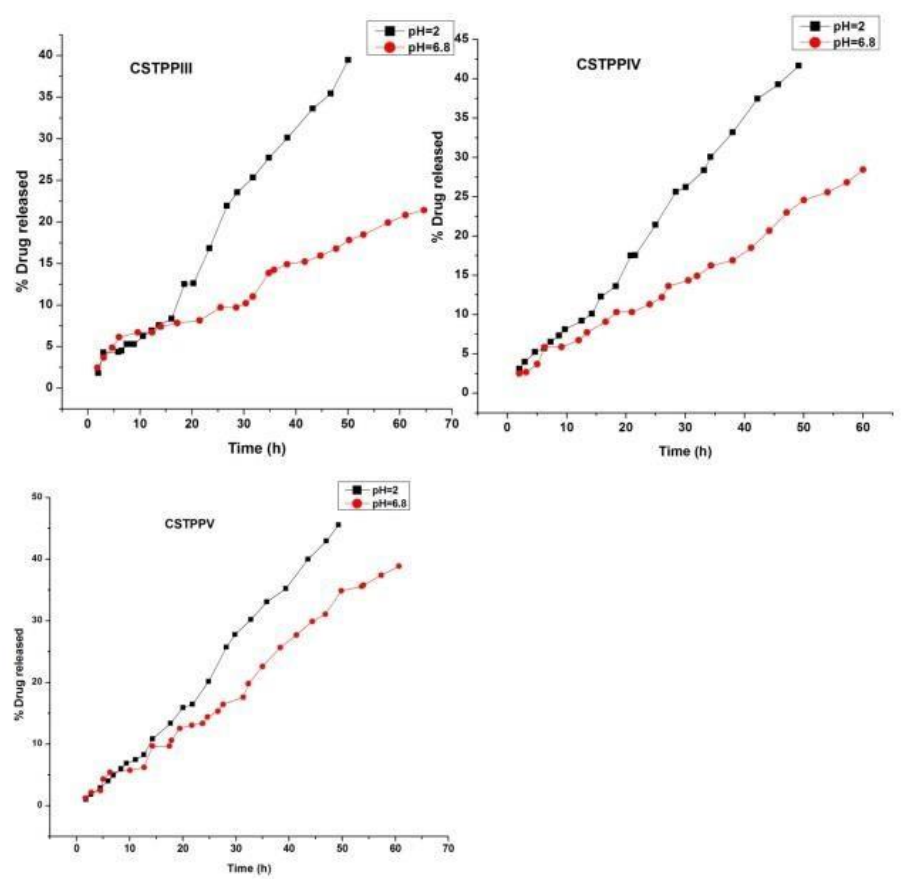

Figure 7: Release of 1,2,4-triazoles (III-V) from CSTPP nanoparticles during time at pH 6.8 and 2. 


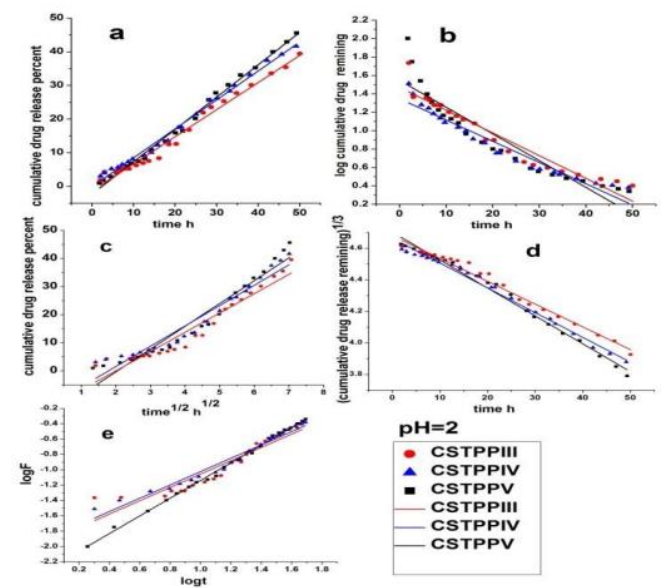

Figure 8: Kinetics of 1,2,4-triazoles (III-V ) released from CSTPP nanoparticles (a): Zero-order, (b): Firstorder, (c): Higuchi model, (d): Hixson-Crowell, (e): Korsmeyer-Peppas equation at pH 2.

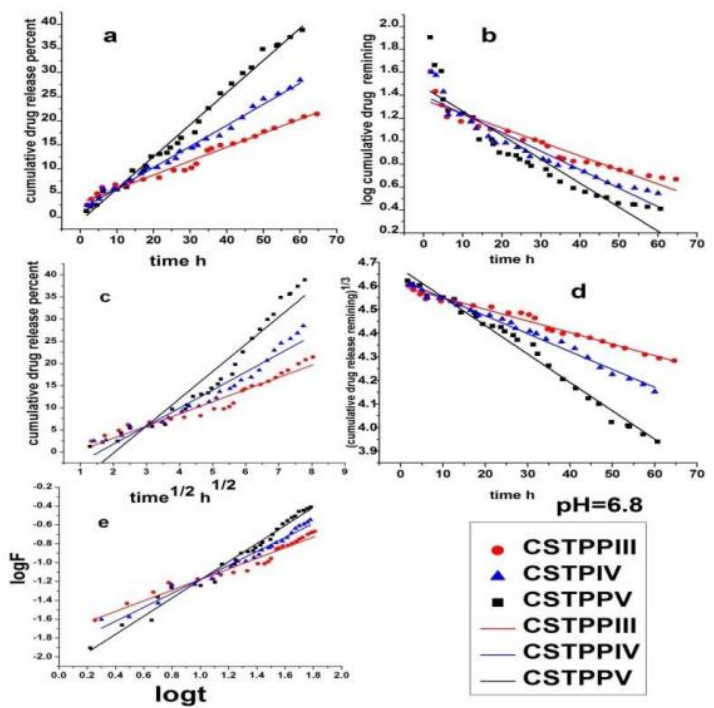

Figure 9: Kinetics of 1,2,4-triazoles (III-V ) released from CSTPP nanoparticles (a): Zero-order, (b): Firstorder, (c): Higuchi model, (d): Hixson-Crowell, (e): Korsmeyer-Peppas equation at pH 6.8 .

Table 2 Controlled release kinetics of 1,2,4-triazoles (III-V) released from CSTPP nanoparticles.

\begin{tabular}{|c|c|c|c|c|c|c|c|c|c|c|c|c|}
\hline \multirow[t]{2}{*}{ Code } & \multirow[t]{2}{*}{$\begin{array}{l}\mathbf{p} \\
\mathbf{H}\end{array}$} & \multicolumn{2}{|c|}{ Zero order } & \multicolumn{2}{|l|}{$\begin{array}{l}\text { First- } \\
\text { order }\end{array}$} & \multicolumn{2}{|l|}{$\begin{array}{l}\text { Higuch } \\
\text { i }\end{array}$} & \multicolumn{2}{|l|}{$\begin{array}{l}\text { Hixson- } \\
\text { Crowell }\end{array}$} & \multicolumn{2}{|c|}{$\begin{array}{c}\text { Korsmeyer- } \\
\text { Peppas }\end{array}$} & \multirow[b]{2}{*}{$\mathbf{R}^{2}$} \\
\hline & & $\mathbf{k}_{\text {。 }}$ & $\mathbf{R}^{2}$ & $\mathbf{k}_{1}$ & $\mathbf{R}^{2}$ & kH & $\mathbf{R}^{2}$ & kHix & $\mathbf{R}^{2}$ & $\log k$ & $\mathbf{n}$ & \\
\hline \multirow{3}{*}{$\begin{array}{c}\text { CSTPPII } \\
\text { I }\end{array}$} & 6. & 0.289 & .9795 & - & 0.8982 & 2.7458 & 0.9365 & - & 0.9790 & 0.018 & .5636 & 0.9526 \\
\hline & 8 & & 8 & 0.0122 & 7 & 3 & 4 & 0.00489 & 4 & 1 & 5 & 3 \\
\hline & 2 & $\begin{array}{c}0.8046 \\
5\end{array}$ & $\begin{array}{c}0.9725 \\
6\end{array}$ & $\begin{array}{c}- \\
0.0247 \\
3\end{array}$ & $\begin{array}{c}0.9181 \\
9\end{array}$ & 6.8751 & $\begin{array}{c}0.9258 \\
9\end{array}$ & $\begin{array}{c}0.01144 \\
4\end{array}$ & $\begin{array}{c}0.9799 \\
6\end{array}$ & $\begin{array}{c}0.008 \\
2\end{array}$ & $\begin{array}{c}0.9555 \\
6\end{array}$ & $\begin{array}{c}0.9403 \\
6\end{array}$ \\
\hline \multirow[t]{2}{*}{$\begin{array}{c}\text { CSTPPI } \\
\mathrm{V}\end{array}$} & $\begin{array}{l}6 . \\
8\end{array}$ & 0.4376 & $\begin{array}{c}0.9920 \\
1\end{array}$ & $\begin{array}{c}- \\
0.0161 \\
6\end{array}$ & $\begin{array}{c}0.8967 \\
2\end{array}$ & $\begin{array}{c}4.0722 \\
9\end{array}$ & $\begin{array}{c}0.9438 \\
7\end{array}$ & $\begin{array}{c}- \\
0.00757\end{array}$ & $\begin{array}{c}0.9885 \\
9\end{array}$ & $\begin{array}{c}0.012 \\
1\end{array}$ & 0.7402 & $\begin{array}{c}0.978 \\
4\end{array}$ \\
\hline & 2 & $\begin{array}{c}0.8594 \\
2\end{array}$ & $\begin{array}{c}0.9923 \\
2\end{array}$ & $\begin{array}{c}- \\
0.0231\end{array}$ & $\begin{array}{c}0.9308 \\
7\end{array}$ & 7.2396 & $\begin{array}{c}0.9402 \\
8\end{array}$ & -0.0157 & $\begin{array}{c}0.9882 \\
4\end{array}$ & $\begin{array}{c}0.012 \\
8\end{array}$ & $\begin{array}{c}0.8676 \\
1\end{array}$ & $\begin{array}{c}0.9686 \\
6\end{array}$ \\
\hline \multirow[t]{2}{*}{ CSTPPV } & $\begin{array}{l}6 . \\
8\end{array}$ & 0.6644 & $\begin{array}{c}0.9891 \\
2\end{array}$ & $\begin{array}{c}- \\
0.0209 \\
1\end{array}$ & 0.859 & $\begin{array}{c}6.1464 \\
7\end{array}$ & $\begin{array}{c}0.9293 \\
3\end{array}$ & -0.0120 & $\begin{array}{c}0.9838 \\
3\end{array}$ & $\begin{array}{c}0.007 \\
2\end{array}$ & $5226 . .0$ & $\begin{array}{c}0.9784 \\
4\end{array}$ \\
\hline & 2 & $\begin{array}{c}0.9603 \\
7\end{array}$ & $\begin{array}{c}0.9939 \\
8\end{array}$ & $\begin{array}{c}- \\
0.0290\end{array}$ & $\begin{array}{c}0.8544 \\
9\end{array}$ & $\begin{array}{c}8.1241 \\
2\end{array}$ & $\begin{array}{c}0.9428 \\
7\end{array}$ & -0.0167 & $\begin{array}{c}0.9883 \\
4\end{array}$ & 0.005 & 1.1519 & $\begin{array}{c}0.9969 \\
8\end{array}$ \\
\hline
\end{tabular}

\section{Conclusion}

A one step route to synthesize CS/triazole derivatives/TPP nanoparticles was developed. This method is imperative in order to produce small particle size with an average size of $21,14.6,23.95,29.5 \mathrm{~nm}$ and their SD were $\pm 5, \pm 5.3, \pm 5.3$, $\pm 7.9 \mathrm{~nm}$ for CSTPP, CSTPPIII, CSTPPVI and CSTPPVII, respectively. The release rate depend on the $\mathrm{pH}$ of the medium and the substituents on 1,2,4-triazoles. The drug release in CSTPPIII, CSTPPIV and CSTPPV at pH 2 is following Zero- 
order kinetics, however, in pH 6.8 is following HixsonCrowell, Zero-order kinetics and Korsmeyer-Peppas equation, respectively. By applying Krosmeyer-Peppas equation the release of triazole derivatives from nanoparticles follows non fickian diffusion. Nanoparticles exhibited antibacterial activity against Gram positive and Gram negative bacteria.

\section{References}

[1].Hamidi M, Azadi A, Rafiei P. Hydrogel nanoparticles in drug delivery. Adv Drug Deliv Rev 2008; 60:1638-1649.

[2].Olteanu CE. Application of functionalized chitosan. Scientific Study \& Research 2007; VIII(3):256-277.

[3].Gavhane YN, Gurav AS, Yadav AV. Chitosan and Its applications: A review of literature. IJRPBS 2013; 4(1):312331.

[4].Fan W, Yan W, Xu Z, Ni H. Formation mechanism of monodisperse, low molecular weight chitosan nanoparticles by ionic gelation technique. Colloids Surf, B 2012; 90:21-27.

[5].Zhang H, Alsarra IA, Neau SH. An in vitro evaluation of a chitosan contain in gmultiparticulate system for macromolecule delivery to the colon. Int J Pharm 2002; 239:197-205.

[6].Ibezim EC, Andrade CT, Marcia C, Barretto B, Odimegwu DC, De Lima FF. Ionically cross-linked chitosan/tripolyphosphate microparticles for the controlled delivery of pyrimethamine. Ibnosina J Med BS 2011; 3(3):77-88.

[7].Konecsni K, Low NH, Nickerson MT. Chitosan-tripolyphosphate submicron particles as the carrier of entrapped rutin. Food Chem 2012; 134:1775-1779.

[8].Hosseini SF, Zandi M, Rezaei M, Farahmandghavi F. Two-step method for encapsulation of oregano essential oil in chitosan nanoparticles, Preparation, characterization and in vitro release study. Carbohydr Polym 2013; 95:50-56.

[9].Hu B, Pan C, Sun Y, Hou Z, Ye H, Hu B, Zeng XX. Optimization of fabrication parameters to produce chitosantripolyphosphate nanoparticles for delivery of tea catechins. J Agric Food Chem 2008; 56:74517458.

[10]. Hemant KSY, Singh MN, Shivakumar HG. Chitosan/sodium tripolyphosphate cross linked microspheres for the treatment of gastric ulcer. Der Pharmacia Lettre 2010; 2(6):106-113.

[11]. Sharma V, Shrivastava B, Bhatia R, Bachwani M, Khandelwal R, Ameta J. Exploring potential of 1,2,4triazole: A brief review. Pharmacologyonline 2011; (1):1192-1222.

[12]. Weidinger H, Kranz J. Synthesen mit imidsäureestern, II. Synthese von 1,3,4-thiodiazolen. Chem Ber 1963; 96(4):1059-1063.

[13]. Cansiz A, Çetin A, Kutulay P, Koparir M. Synthesis of tautomeric forms of 5-(2-Hydroxyphenyl)-4-substituted-3H1,2,4-triazole-3-thione. Chem Asian J 2009; 21(1):617-626.

[14]. Lawrie G, Keen I, Drew B, Chandler-Temple A, Rintoul L, Fredericks P, Grøndahl L. Interactions between alginate and chitosan biopolymers characterized using FTIR and XPS. Bio-macromolecules 2007; 8:2533-2541.

[15]. Zamora-Mora V, Fernández-Gutiérrez M, San Román J, Goya G, Hernández R, Mijangos C. Magnetic core-shell chitosan nanoparticles, rheological characterization and hyperthermia application. Carbohydr Polym 2014; 102:691-698.

[16]. Jingou J, Shilei H, Weiqi L, Danjun W, Tengfei W, Yi X. Preparation characterization of hydrophilic and hydrophobic drug in combine loaded chitosan/cyclodextrin nanoparticles and in vitro release study. Colloids Surf, B 2011; 83:103-107.

[17]. Tang ESK, Huang M, Lim LY. Ultrasonication of chitosan and chitosan- nanoparticles. Int J Pharm 2003; 265:103114.

[18]. Qi L, Xu Z, Jiang X, Hu C, Zou X. Preparation and antibacterial activity of chitosan nanoparticles. Carbohydr Res 2004; 339:2693-2700.

[19]. Peniche C, Zaldivar D, Bulay A, Roman JS. Study of the thermal degradation of poly (furfuryl methacrylate) by thermogravimetry. Polym Degrad Stab1993; 40:287-295.

[20]. Helander IM, Nurmiaho-Lassila EL, Ahvenainen R, Rhoades J, Roller S. Chitosan disrupts the barrier properties of the outer membrane of Gram-negative bacteria. Int J Food Microbiol 2001; 71:235-244. 